\title{
PENGARUH MEDITASI DZIKIR TERHADAP PERUBAHAN TEKANAN DARAH PADA PASIEN HIPERTENSI
}

\author{
Rika Purnika ${ }^{1}$, Bambang Roesmono², Kassaming ${ }^{3}$ \\ ${ }^{1}$ STIKES Muhammadiyah Sidrap \\ ${ }^{2}$ STIKES Muhammadiyah Sidrap \\ ${ }^{3}$ STIKES Muhammadiyah Sidrap
}

Alamat korespondensi: (rikapurnika@gmail.com/082192760410)

\begin{abstract}
ABSTRAK
Tindakan keperawatan yang dapat dilakukan untuk mengurangi tekanan darah pada penderita hipertensi berupa pemberian teknik nonfamakologi yaitu meditasi dzikir. Tujuan penelitian yaitu untuk mengetahui pengaruh meditasi dzikir terhadap perubahan tekanan darah pada pasien hipertensi di Ruang interna RSUD Nene Mallomo Kabupaten Sidenreng Rappang. Penelitian ini merupakan penelitian kuantitatif dengan metode penelitian quasi eksperimen dengan desain pre dan post test design tanpa kelompok kontrol yang dilakukan pada tanggal 19 Juni sampai dengan 19 Juli Tahun 2019 diruang Interna RSUD Nene Mallomo Kabupaten Sidenreng Rappang. Teknik pengambilan sampel yaitu purposive sampling dengan jumlah sampel sebanyak 15 responden.Analisa data yang digunakan adalah uji paired T-test. Hasil penelitian ini di dapatkan nilai $p=0,001$ dengan tingkat kemaknaan $p<\alpha(0,05)$ yang dimana nilai $p<\alpha$ maka dapat di simpulkan bahwa ada Pengaruh Meditasi Dzikir Terhadap Perubahan Tekanan Darah Pada Pasien hipertensi diRuang Interna RSUD Nene Mallomo Kabupaten Sidenreng Rappang. Hasil penelitian ini dapat di pergunakan sebagai bahan masukan bagi institusi kesehatan dalam memberikan meditasi dzikir sebagai terapi non farmakologi untuk menurunkan tekanan darah, khususnya pada pasien hipertensi.
\end{abstract}

Kata Kunci: Hipertensi, Tekanan Darah, Meditasi Dzikir

\section{PENDAHULUAN}

Sistem kardiovaskuler merupakan sistem yang berhubungan dengan jantung dan pembuluh darah.Sistem kardiovaskuler berfungsi sebagai sistem regulasi melakukan berbagai mekanisme yang bervariasi dalam merespon seluruh aktivitas dalam tubuh. Adapun komponene sistem kardiovaskuler yang mempengaruhi stabilnya organ-organ vital yaitu jantung, komponen darah dan pembuluh darah. Ketiga komponen tersebut harus berfungsi dengan baik agar seluruh jaringan dan organ tubuh menerima suplai oksigen dan nutrisi dengan baik. Apabila ketiga komponen tersebut tidak berfungsi dengan baik akan menimbulkan dampak buruk bagi kesehatan sehingga muncul beberapa penyakit diantarannya yaitu aterosklerosis, angina pektoris, infark miokardium, dan hipertensi (Udjianti, 2013 dalam Fadli, 2018).

Hipertensi tidak hanya beresiko tinggi menderita penyakit jantung,tetapi juga menderita penyakit lain seperti penyakit saraf,ginjal,dan pembuluh darah dan makin tinggi tekanandarah,makin besar resikonya. Hipertensi adalah sebagai peningkatan tekanan darah sistolik sedikitnya $140 \mathrm{mmHg}$ atau tekanan diastoliknya $90 \mathrm{mmHg}$ (Nurarif \& Kusuma, 2015).
Badan penelitian kesehatan dunia World Health Organization (WHO) Tahun 2015 salah satu penyebab utama kematian dini disuluruh dunia adalah Hipertensi. Dimana hampir 1 milyar orang diseluruh dunian memiliki tekanan darah tinggi. Di tahun 2020 sekitar 1,56 miliar orang dewasa akan hidup dengan hipertensi. Setiap tahun didunia hampir 8 milyar orang meninggal karna hipertensi dan di kawasan AsiaTimur Selatan hampir 1,5 juta orang setiap tahunnya. Sekitar sepertiga dari oarang dewasa di Asia Timur-Selatan menderita hipertensi.

Berdasarkan data Dinkes tahun 2015 prevelensi hipertensi di sulawesi Selatan tahun 2014 yang didapat melalui pengukuran pada umur $>18$ tahun sebesar $28,1 \%$, tertinggi di Enrekang (31,3\%), diikuti Bulukumba $(30,8 \%)$, Sinjai $(30,4 \%)$, Gowa $(29,2 \%)$. Prevalensi hipertensi di Sulawesi Selatan yang didapat melalui koesioner yang didiagnosis tenaga kesehatan terbesar $10,3 \%$, yang didiagnosis tenaga kesehatan atau sedang minum obat sebesar $10,5 \%$, sehingga ada 0,2 $\%$ yang minum obat sendiri (Fadli, 2018).

Berdasarkan Riset Kesehatan Dasar (riskesdas) tahun 2018 prevelensi hipertensi berdasarkan klasifikasi umur yaitu umur 18 $24(13,22 \%), 25-34(20,13 \%)$, sedangkan umur 35 - 44 (31,61\%). Sedangkan untuk 
prevelensi berdasarkan jenis kelamin kebanyakan perempuan $(36,85 \%)$. Hipertensi tertinggi di provinsi kalimantan selatan $(44,13$ $\%$ ) dan terendah di provinsi papua ( $22,22 \%$ ), sedangkan untuk wilayah selawesi selatan sebanyak $(31,68 \%)$ yang didapat melelui pengukuran pada penduduk umur $>18$ tahun (kementerian Kesehatan RI, 2018).

Penanganan untuk hipertensi dapat dilakukan dengan dengan farmakologi diantaranya menggunakan golongan obat deuretik, simpolitik, penghabat adrenegik-alfa, penghambat neuron adrenergik dan vasodilator arteriol,penanganan nonfarmakologi dapat dilakukan dengan olahraga pernapasan, pelemasan otot, penurunan berat badan, pembatasan alkohol, natrium, dan tembakau, olahraga ringan, dan relaksasi (Finaldiansyah, 2016).

Relaksasi dalam agama Islam itu menggunakan bacaan-bacaan dzikir (mengingat Allah) dengan mengulang-ulang bacaan tertentu.kemiripan antara relaksasi dengan dzikir terletak pada upaya pengkonsentrasian pikiran, upaya melepaskan diri dari segala sesuatu yang mengganggu pikiran, keduanya juga sejalan dalam hal latihan, dan mengulang kata-kata atau makna meditasi (Finaldiansyah, 2016).

Tindakan keperawatan dengan menggunakan meditasi dzikir terhadap tekanan darah pada pasien hipertensi masih jarang dilakukan oleh perawat di ruang perawatan Rumah Sakit Nene Mallomo Kabupaten Sidenreng Rappang. Sehingga penelitian ini bertujuan untuk melakukan penelitian tentang pengaruh meditasi dzikir terhadap perubahan tekanan darah pada pasien hipertensi di rumah sakit Nene Mallomo Kabupaten Sidenreng Rappang.

\section{BAHAN DAN METODE}

Lokasi, Populasi, dan Sampel

Penelitian ini telah dilakukan di ruang interna Rumah Sakit Nene Mallomo Kebupaten Sidenreng Rappang pada tahun 2019. Populasi dalam peneltian ini adalah semua pasien hipertensi dan sample pada penelitian ini adalah pasien yang menderita hipertensi sesuai dengan kriteria yang telah ditentukan dengan jumlah sampel 15 responden. Teknik pengambilan sampel menggunakan purposive sampling.adapun kriteria sample pada penelitian ini sebagai berikut :

1. Kriteria inklusi :

a. Pasien hipertensi yang beragama islam

b. Pasien yang tingkat kesadaranya compos mentis c. Tekanan darah sistolik pasien diatas $140 \mathrm{mmHg}$ dan tekanan diastoliknya diatas $90 \mathrm{mmHg}$

d. Pasien yang bersediah menjadi responden

2. Kriteria eksklusi :

a. Pasien hipertensi yang tidak beragama islam (non muslim)

b. Pasien yang mengalami penurunan kesadaran

c. Tekanan darah sistolik dibawah 140 $\mathrm{mmHg}$ dan tekanan diastoliknya dibawah $90 \mathrm{mmHg}$

d. Pasien yang tidak bersedia menjadi responden

\section{Pengumpulan Data}

1. Data primer merupakan data yang didapatkan langsung oleh seorang peneliti dalam hal ini, data pasien hipertensi yang memenuhi kriteria penelitian.

2. Data sekunder merupakan data yang diambil dari rekam medik rumah sakit Nene Mallomo Kebupaten Sidenreng Rappang.

\section{Pengolahan Data}

1. Editing dilakukan oleh peneliti untuk memeriksa kembali kebenaran data yang berhubungan dengan tujuan penelitian.

2. Coding dilakukan oleh peneliti untuk memberikan pengkodean data pada saat peneliti ingin melakukan pengolahan data yang terkait dengan data numerik dan data kategorik.

3. Entri data dilakukan oleh peneliti pada saat memasukkan data pada master tabel atau pada komputer untuk melakukan pengolahan atau analisis data.

\section{Analisis Data}

1. Analisis Univariat merupakan analisa data untuk mengetahui hasil setiap variabel dalam penelitian yang disajikan pada tabel distribusi frekuensi berupa data demografi, nilai rerata tekanan darah sebelum dan setelah intervensi.

2. Analisis Bivariat merupakan analisis data untuk mengetahui pengaruh antara variabel independen dengan variabel dependen adapun uji analisis yang digunakan adalah uji Paired T test.

\section{HASIL PENELITIAN}

1. Analisis Univariat

Tabel 1. Tekanan darah sebelum intervensi. $(n=15)$

\begin{tabular}{|c|c|c|c|}
\hline Variabel & $\mathrm{n}$ & Mean & Min-Max \\
\hline TDS Pre & 15 & 174,00 & $140-210$ \\
\hline TDD Pre & 15 & 104,00 & $90-140$ \\
\hline
\end{tabular}


Tabel 1 menunjukkan bahwa uji analisis univariat tekanan darah sistol didapatkan nilai rata-rata tekanan darah sistol sebelum intervensi yaitu hasil mean 174,00 , nilai minimum 140 dan nilai maximum 10. Sedangakn uji analisis univariat didapatkan nilai rata-rata tekanan darah diastol sebelum intervensi yaitu hasil mean 104,0, nilai minimum 90 dan nilai maximum 140 .

Tabel 2. Tekanan darah setelah intervensi. $(\mathrm{n}=15)$

\begin{tabular}{|c|c|c|c|}
\hline Variabel & $\mathrm{n}$ & Mean & Min-Max \\
\hline TTS Pre & 15 & 1,42 & $83,3-163,3$ \\
\hline TDD Post & 15 & 93,55 & $80,0-106,7$ \\
\hline
\end{tabular}

Tabel 2 menunjukkan bahwa uji analisis univariat didapatkan nilai rata-rata tekanan darah sistol setelah intervensi didapatkan hasil mean 1,42 , nilai minimum 83,3 dan nilai maximum 163,33. dan uji analisis univariat didapatkan nilai rata-rata tekanan darah diastol setelah intervensi didapatkan hasil mean 93,55, nilai minimum 80,0 dan nilai maximum 106,7.

2. Analisis Bivariat

Tabel 3. Pengaruh meditasi dzikir terhadap perubahan tekanan darah sistol pada pasien hipertensi. $(n=15)$

\begin{tabular}{|c|c|c|c|c|c|}
\hline TDS & $\mathrm{n}$ & \multirow{2}{*}{ Mean } & \multicolumn{2}{|c|}{$\mathrm{Cl} 95 \%$} & \multirow{2}{*}{$P$} \\
\cline { 4 - 5 } & & & Min & Max & \\
\hline $\begin{array}{l}\text { Pre- } \\
\text { Post }\end{array}$ & 15 & 3,13 & 24,3 & 28,3 & 0,000 \\
\hline
\end{tabular}

Tabel 3 menunjukkan bahwa selisih rerata tekanan darah sistol pada tekanan darah pasien hipertensi sebelum dan setelah intervensi $3,13 \mathrm{mmHg}$ dan nilai $\mathrm{P}=0,000$, artinya ada perbedaan antara rerata sebelum dan setalah diberikan intervensi, sehinnga ada pengaruh yang signifikan pemberian meditasi dzikir terhadap perubahan tekanan darah sistol pada pasien hipertensi

Tabel 4. Pengaruh meditasi dzikir terhadap perubahan tekanan darah sistol pada pasien hipertensi. $(n=15)$

\begin{tabular}{|c|c|c|c|c|c|}
\hline TDD & $\mathrm{n}$ & Mean & \multicolumn{2}{|c|}{ Cl 95\% } & \multirow{2}{*}{$P$} \\
\cline { 4 - 5 } $\begin{array}{l}\text { Pre- } \\
\text { Post }\end{array}$ & 15 & 1,04 & 5,71 & 15,7 & 0,001 \\
\hline
\end{tabular}

Tabel 4 menunjukkan bahwa selisih rerata tekanan darah diastol pada tekanan darah pasien hipertensi sebelum dan setelah intervensi $1,04 \mathrm{mmHg}$ dan nilai $\mathrm{P}=0,001$, artinya ada perbedaan antara rerata sebelum dan setalah diberikan intervensi, sehinnga ada pengaruh yang signifikan pemberian meditasi dzikir terhadap perubahan tekanan darah diastol pada pasien hipertensi

\section{PEMBAHASAN}

Dari hasil uji paired $T$ test dengan tingkat kemaknaan $\alpha=(0,05)$, didapatkan nilai $p$ sebesar 0,000 , nilai $\mathrm{p}<0,05$, yang berarti $\mathrm{Ha}$ diterima dan dari hasil uji paired $T$ test dengan tingkat kemaknaan $a=(0,05)$, didapatkan nilai $p$ sebesar 0,001 , nilai $\mathrm{p}<0,05$, yang berarti $\mathrm{Ha}$ diterima dan Ho ditolak. Jadi, hasil dari penelitian ini menunjukkan bahwa pemberian meditasi dzikir dapat menurunkan tekanan darah pada pasien hipertensi

Hasil penelitian ini sejalan dengan penelitian yang dilakukan oleh lulu mengatakan bahwa saat dzikir telah menembus seluruh bagian tubuh bahkan kesetiap sel-sel dari tubuh itu sendiri, hal ini akan berpengaruh terhadap tubuh (fisik) dengan getaran rasa yang lemas dan pada saat itulah tubuh manusia merasakan rileksasi saraf sehingga ketegganganketegangan yang dirasakan akan hilang (Kumala, Kusprayogi, \& Nashori, 2017).

Hasil penelitian ini juga sejalan dengan penelitian yang dilakukan oleh Finaldiansyah (2016) tentang pengaruh dzikir terhadap penurunan tekanan darah pada usia pertengahan di wilayah kerja UPK puskesmas kampung dalam kecematan pontianak timur. Hasil penelitian yang dilakukan peneliti didapatkan perubahan yang signifikan tekanan darah sebelum dan sesudah intervensi dengan nilai $\quad p=0,000$, rata-rata penurunan tekanan darah sistol $9,28 \mathrm{mmHg}$, sedangkan rata-rata penurunan tekanan darah diastol 6,50 mmHg (Finaldiansyah, 2016).

Pada penelitian ini rata-rata tekanan darah sistol sebelum dilakukan meditasi dzikir pada pasien hipertensi yaitu 174,00 dengan nilai minimum 140, nilai maksimum 210 dan ratarata tekanan darah sistol setelah diberikan meditasi dzikir yaitu 1,42, dengan nilai minimum 83,33, nilai maksimum163,33.

Tekanan sistol salah satunya dipengaruhi oleh psikologis sehingga dengan relaksasi akan mendapatkan ketenangan dan tekanan sistol akan turun, selain itu tekanan darah sistol juga dipengaruhi sirkulasi sistemik dan sirkulasi pulmonal sehingga dengan relaksasi meditasi yang berfokus pada pemusatan pikiran dan pengaturan pernafasan akan terjadi penurunan nadi dan penurunan tekan darah sistol (Potter \& Perry, 2010).

Pada penelitian ini rata-rata tekanan darah diastol sebelum dilakukan meditasi dzikir pada 
pasien hipertensi yaitu 104,00 dengan nilai minimum 90, nilai maksimum 140 dan ratarata tekanan darah diastol setelah diberikan meditasi dzikir yaitu 93,55, dengan nilai minimum 80,00, nilai maksimum 106,67. Tekanan darah diatol terkait dengan sirkulasi koroner, jika ateri koroner mengalami ateroklerosis akan mempengaruhi peningkatan tekanan darah diastol, sehingga dengan meditasi mengalami penurunan tekanan diastol yang berarti sesudah diberikan meditasi dzikir (Haryono, Permana, \& Chayati, 2017).

Pada penelitian ini peneliti menggunakan handphone dan haenset sebagai alat pendengar suara (dzikir) dengan menggunakan haenset dapat membatu pasien untuk menfokuskan pikiran dan berkonsentrasi terhadap dzikir yang didengarkan sehingga menurunkan tekana darah sistol dan diastol.

Meditasi dzikir menyebabkan terkendalinya hormon epinefrin dan norepinefrin oleh medulla adrenal. Terkendalinya hormon epinefrin dan norepinefrin akan menghambat pembentukan angiotensin akibat terjadinya penurunan denyut jantung, pembuluh darah melebar, tahanan pembuluh darah berkurang dan penurunan pompa jantung sehingga tekana arteri jantung menurun yang selanjutnya dapat menurunkan tekanan darah.

Pada dasarnya pemberian terapi meditasi ini dapat memberikan kondisi yang rileks dimana pada kondisi rileks yang rileks dimana pada kondisi rileks semua siystem tubuh akan bekerja dengan baik dan pada kondisi ini hipotalamus akan menyesuaikan dan terjadinya penurunan aktivitas sistem saraf simpatis dan meningkatkan aktivitas sistem parasimpatis. Urutan efek fisiologis dan gejala maupun tandanya akan terputus dan stress psikologi akan berkurang. Teknik relaksasi otot, relaksasi dengan imajinasi terbimbing dan respon relaksasi dari Benson. Hasil penelitian ini sesuai dengan teori yang mengatakan bahwa terapi meditasi adalah salah satu metode untuk membantu menurunkan tekanan darah.

Penurunan tekanan darah disebabkan karna relaksasi meditasi pada perinsipnya adalah memposisikan tubuh dalam kondisi tenang, sehingga akan mengalami kondisi keseimbangan, dengan demikian relaksasi meditasi yang berintikan pada pernafasan akan kondisi rileks semua siystem tubuh akan bekerja dengan baik dan pada kondisi ini hipotalamus akan menyesuaikan dan terjadinya penurunan aktivitas sistem saraf simpatis dan meningkatkan aktivitas sistem parasimpatis (Kozier, 2010).

Urutan efek fisiologis dan gejala maupun tandanya akan terputus dan stress psikologi akan berkurang. Teknik relaksasi otot, relaksasi dengan imajinasi terbimbing dan respon relaksasi dari Benson. Hasil penelitian ini sesuai dengan teori yang mengatakan bahwa terapi meditasi adalah salah satu metode untuk membantu menurunkan tekanan darah.

Penurunan tekanan darah disebabkan karna relaksasi meditasi pada perinsipnya adalah memposisikan tubuh dalam kondisi tenang, sehingga akan mengalami kondisi keseimbangan, dengan demikian relaksasi meditasi yang berintikan pada pernafasan akan Responden menyatakan bahwa setelah mendengarkan dzikir mereka mendapatkan ketenagan karna dapat mendekatkan diri kepada sang pencipta Allah SWT. Mendengarkan dzikir mengajarkan pasien untuk merendahkan diri kepada Allah, mengfokuskan dan menjernihkan pikiran. Dzkir dengan penuh keikhlasan dan penghayatan akan membawa individu berada dalam keadaan yang tenang dan nyaman.

Terapi dzikir dapat mempengaruhi intensitas nyeri pada pasien gastrtitis karena dalam pemberian terapi dzikir dilakukan selama 15-20 menit dan dilaksanakan 5-6 jam sebelum pasien diberikan tindakan farmakologi (Fadli, Resky, \& Sastria, 2019).

\section{KESIMPULAN}

Terdapat perubahan yang signifikan selisih rerata tekanan darah sistol sebelum dan setelah diberikan meditasi dzikir pada pasien hipertensi yaitu 3,13 dengan nilai $P=0,000$, sehingga ada pengaruh yang signifikan pemberian meditasi dzikir terhadap perubahan tekanan darah sistol pada pasien hipertensi. Sedangan selisih rerata tekanan darah diastol sebelum dan setelah diberikan meditasi dzikir pada pasien hipertensi yaitu 1,04 dengan nilai $P=0,001$, sehingga ada pengaruh yang signifikan pemberian meditasi dzikir terhadap perubahan tekanan darah diastol pada pasien hipertensi.

\section{SARAN}

Bagi pihak rumah sakit agar dapat mengembangkan protap/SOP intervensi keperawatan pada pasien hipertensi dalam mencegah masalah peningkatan tekanan darah sehingga semua perawat wajib mengimplementasikan kepada pasien. 


\section{DAFTAR PUSTAKA}

Fadli, F. (2018). Pengaruh Relaksasi Otot Progrisif Terhadap Perubahan Tekanan Darah Pada Pasien Hipertensi . Jurnal Ilmiah Kesehatan Diagnosis Volume 12 Nomor 3 , 249. Retrieved From http://www.ejournal.stikesnh.ac.id/index.php/jikd/article/view/315

Fadli, F., Resky, R., \& Sastria, A. (2019). Pengaruh Terapi Dzikir terhadap Intensitas Nyeri pada Pasien Gastritis. Retrieved From http://www.ejurnal.poltekkes-tjk.ac.id/index.php/JK/article/view/1192

Finaldiansyah, R. (2016). naska publikasi. pengaruh dzikir terhadap penurunan tekanan darah pada usia pertengahan di wilayah kerta upk puskesmas kampung dalam kecematan pontianak timur , 3 - 4.

Haryono, R., Permana, I., \& Chayati, N. (2017). Pengaruh Kombinasi Pijat Punggung Dan Dzikir Terhadap Tekanan Darah. Jurnal Keperawatan Notokusumo Volume V No 1 , 4-5.

Kementerian Kesehatan RI. (2018). Profil Kesehatan Kementerian Kesehatan Rupublik Indonesia.

Kumala, O. D., Kusprayogi, Y., \& Nashori, F. (2017). Epektivitas Pelatihan Dzikir dalam Meningkatkan Ketenangan Jiwa Pada Lansia Penderita Hipertensi. Jurnal Ilmiah Psikologi Vol. 4, No.1, 59-60.

Kozier, B. M. R. (2010). Fundamental Keperawatan. Konsep, Proses \& Praktik. Jakarta: EGC.

Natoatmojo, S. (2012). Metodologi Penelitian Kesehatan. Jakarta: Rineka Cipta.

Nurarif, A. H., \& Kusuma, H. (2015). Aplikasi Asuhan Keperawatan Berdasarkan Diagnosa Medis Dan Nanda Nic Noc. Yogyakarta: Mediaction.

Potter, P. A., \& Perry, A. G. (2010). Fundamental of Nursing. Jakarta: EGC. 